\title{
Effects of Overused Top-hammer Drilling Bits
}

\author{
Seunghyuk Hwang ${ }^{1}$ and Hyongdoo Jang ${ }^{2 *}$ \\ ${ }^{1}$ Paddington Operations, Norton Gold Fields Limited, Australia \\ ${ }^{2}$ Western Australian School of Mines: Minerals, Energy and Chemical Engineering, Curtin University, Australia
}

Submission: September 06, 2019; Published: September 25, 2019

*Corresponding author: Hyongdoo Jang, Department of Minerals, Energy and Chemical Engineering, Curtin University, Australia

\begin{abstract}
The drill bits are the foremost common consumables in the mining industry but an essential part of the rock excavation process. The management of the bit wear directly influences the drilling quality and the productivity of the mine but often overlooked as a common consumable part. The study aims to analyze the effects of overused top-hammer drilling bits to various type of bit failure modes. 341 drill bits samples (ST68$102 \mathrm{~mm}$ ) were visually investigated to check the status of overused and failures. The button chipped (BC) type of failure occurs most frequently among all other types of bit failures. Subsequently, a positive correlation between the number of grinding rounds and bit failures were found. In addition, a cost analysis was conducted to demonstrate the adverse effects of drilling with overused bits. The results explicitly show the cost loss of using overused bits as the cost per metre (CPM) of 75\% flat bits calculated to 3.1 AUD per metre while the CPM stays at 1.6 AUD per metre for using rock bits with $30 \%$ flat buttons.
\end{abstract}

Keywords : Rock drill; Bit failure; Button wear; WC/Co; Grinding

\section{Introduction}

In rock drilling, the wear on drill bit button significantly affects its service life and machine operating cost [1]. Thus, continuous failure analysis and performance evaluation of the drill bit is crucially required to reduce the operation cost. Few pieces of research have been conducted on the tungsten carbide (WC/ Co) button failures modes and button wear characteristics. Most studies have focused on microscopy level of WC/Co button failure analysis. For instance, Swick, et al. [2] conducted experiments using microscopy methods on WC/Co button worn surfaces to reveal the bit wear characteristics. The drilling experiments were conducted using a rotary-percussive rock drill with Sandvik Coromant 33mm button bit to three different types of rock, i.e., granite, dolerite and diorite from the Boddington Mine, Western Australia. Rapid tool wear was observed with the granite sample experiencing micro and macro spalling on the bit buttons. Contrast, only micro spalling was monitored on both dolerite and diorite samples of which demonstrated less bit wear than the bit applied to the granite sample. The experiment discovered the critical dependence of drilling efficiency to the scale of rock spalling. Gupta, et al. [3] introduced different wear modes from experiments on the bit scanning electron microscopy (SEM). The research introduced a high qualitative wear classification system through accurate microscopy observations providing a close-range view of button bits figures. The study aims to analyze the effects of overused drill bits to various type of bit failure modes through statistical analysis. In following Section 2 demonstrates the effects of overused drill bit failures, Section 3 explains common bit failure modes, Section 4 , describes the statistical analysis of bit failures from MINE-A, and Section 5 demonstrates an example of an annual cost of bit failures of mines with different production capacities. Section 6 has discussions and conclusions of the study.

\section{The Effects of Overused Bits to Drill Bit Failures}

Drill bit failure is governed by various conditions. The influencing factors of the bit failure can be broadly classified into manufactures, end users, and rock types. Especially, rock properties must be clearly understood to evaluate the performance of drilling and the wear of drilling tools as the rock tool wear is significantly dependent upon the rock type [4]. The hard rock consists with high silica and quartzite generates extremely high pressures that increased the chance of the bit button removal rate, regional failures, and crushes of the tungsten carbide (WC/Co) bit surfaces [5]. Another critical factor to drill bit failures is the overusing. The mining industry often refers it to 'overboard' which is an industrial terminology of overused bits. Industry classifies overboard bits if the diameter of the flat face of the bit button is larger than one-third of the original button diameter. Figure 1 is an example of an overboard ST68-102mm drill bit from MMTC (Mitsubishi Material Trading Corporation) shows flat worn tungsten carbide 
buttons. The overboard bit tends to cause cracked buttons which leads to tremendous adverse effects on the tool efficiency and triggering drill hole deviations. In other words, the rate of button damage increases when a bit is overused. Furthermore, the overboard bit significantly drops the penetration rate. When a wear flat of a button is equivalent to one-third of the button diameter, the penetration rate will be dropped by $5 \%$. Further use of the overboard bit to two third of the wear flat will drop its penetration rate by $30 \%$ [6]. A common industrial practice to extend the drill bit service life is the bit button grinding. The industrial rule of thumb suggests having around 10 times of bit button grinding for the bit sizes around $100 \mathrm{~mm}$. Furthermore, the performance of the entire drilling operation can be significantly enhanced by proper bit button grindings. The grinding of bit buttons naturally causes the tungsten carbide material loss [5]. However, the ideal shape of the button by removing sources of stress concentration should be consistently maintained to protect the WC/Co buttons from catastrophic fractures.

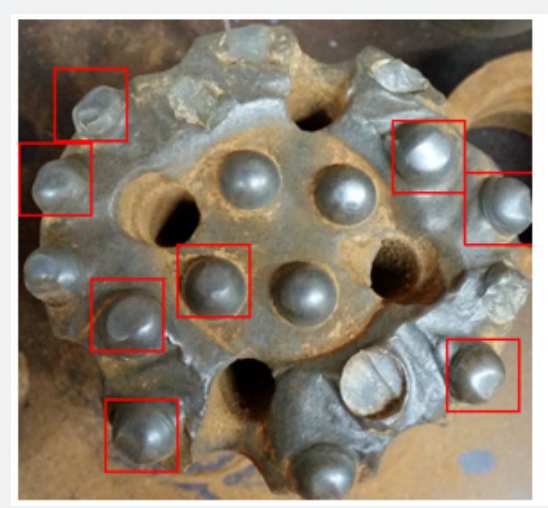

Figure 1: Example of an Overboard Drill bit Having Flat Worn Carbides Indicated in Red Squares (ST68-102mm Drill Bits from Mitsubishi Materials Trading Corporation, Kalgoorlie, WA, Australia).
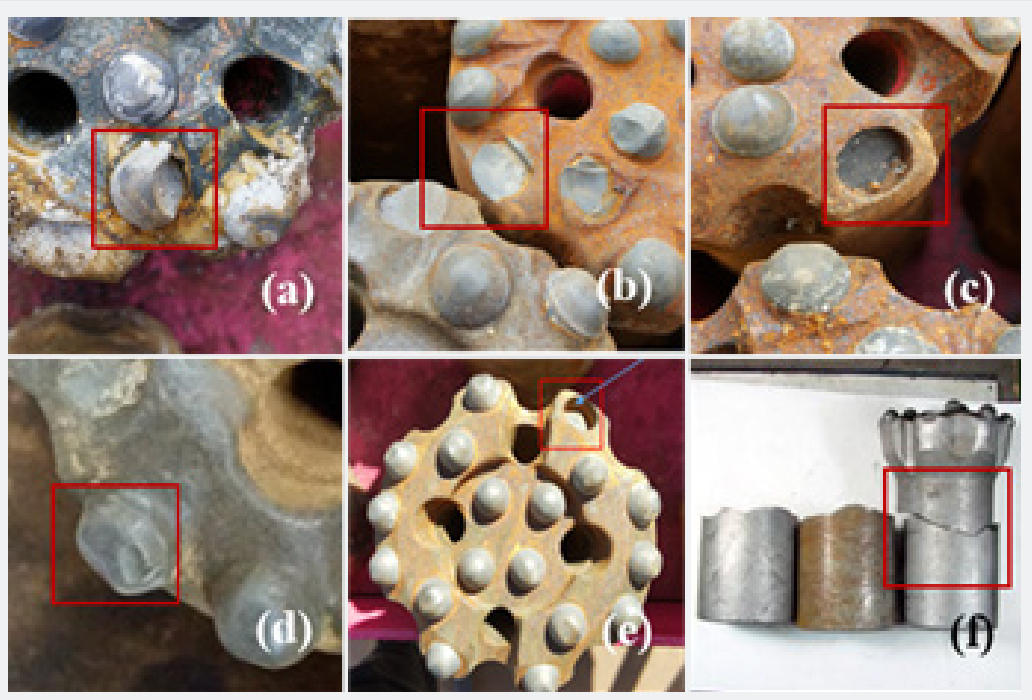

Figure 2: Common Carbide Button Bits Failure Modes.
a) Button chipped.
b) Button sheared-off with body level.
c) Button sheared-off below body level.
d) Cracked carbide.
e) Lost button.
f) Failure at Skirt.

\section{Common Button Bit Failure Modes}

The study focuses the visible classification of each failure mode that occurred during the drilling operation. Thus, knowledge of bit failure modes is critical. In this section, six common bit failure modes and the main causative factors will be introduced. Typical bit failure modes are demonstrated in Figure 2 (a) button chipped

(b) button sheared-off with body level

(c) button sheared-off below body level

(d) cracked tungsten carbide

(e) lost button. 
The main reason for the button chipped (BC) failure is the overboard. If a bit is overused, the overboard causes to create micro-fractures on the WC/Co buttons that are likely developed to further cracks. Figure 2 (a) shows a typical primary breakage on top of the WC/Co button. In excessive condition, trailing edges with more than two chipping progress on the same button crossing through the bottom line of the button. Prior to the button chipped via brittle fracture, the WC/Co undergoes a plastic deformation at an overused carbide component with high-stress concentrations [7]. The button chipped failure can be prevented with a regular inspection of bits to grind the wounded WC/Co surface to remove micro-cracks if necessary. The button chipping phenomenon can also be reduced using a bit with a softer grade WC/Co or increasing rotation speed while drilling [8].

The failure mode button sheared-off with body level (SOW) usually shows a clear flat sheared surface on a button as shown in Figure 2 (b). This failure normally left trailing edges and mainly occurred due to the overuse of bits with poor operational skills. The WC/Co button is often sheared off when encountered with unexpected metallic materials (i.e., rock bolts or cable bolts) during the operation. The failure mode sheared-off button below body level (SOB) has similar features with the SOW failure mode as shown in Figure 2 (c). The failure mode can occur due to the incorrect size correlation between a button and a buttonhole which can be acknowledged as a manufacturing error. The main causative factor of cracked tungsten carbide (CC) failure in Figure 2 (d) is the bit overusing. As the fracturing progressions to the $\mathrm{BC}$ failure, the bit overusing generally creates micro fractures in WC/Co and weakens the WC/Co material. Visible cracks arise from these micro fractures after excessive use of bits and a fine abrasion mechanism is generated. After the material resistance to thermal fatigue is exceeded, small cracks start to grow through the cobalt phase into the tungsten phase. WC/Co grains start to get fragmented into debris and create material. The reptile skin pattern becomes visible once WC/Co starts to fracture and rock debris is pressed into cracks. Subsequently, entire WC/Co grains will be removed by abrasion, which also affects the cobalt phase as well [9]. The lost buttons (LB) failure mode (Figure 2 (e)) rarely occurs as the failure is not caused by the mechanical impacts during the drilling operation. The main cause of the failure mode is the free hammering of the bit in the air. The free hammering generates massive dynamic shock impacts that propagate back and heat up all steel parts of a drill rig. Especially when a bit is free hammered in a borehole, the probability of the failure of gauge buttons is increased as they are easily impacted by the borehole wall. Another main cause of the lost button's failure is improper soldering of the buttons in a bit base steel which can be considered as a manufacturing error [10].

The failure at skirt (FS) mode seldom occurs during the drilling operation which is mainly caused when a bit is excessively used in extraordinary situations. For instance, if an excessive rotational speed is applied, a stuck bit gets heated along the thread inside the steel body which can cause the skirt failure. In addition, incorrect collaring practices could be another reason but material fatigue from excessive hammering is the most common cause of the failure. On the other hand, material failure could be acknowledged as a manufacturing error [10]. In the majority bit failure modes, the regular bit inspection is the most effective method to reduce bit failures. Through the regular inspection, proper grinding intervals of the bit for the given geological condition can be determined to prevent possible bit failures and productivity loss.

\section{Data Analysis and Discussion}

Over a period of 4 months, 341 drill bit samples (ST68$102 \mathrm{~mm}$-MMTC) had been collated. The number of used bits were regularly sent to a bit grinding service center from MINE-A, Kalgoorlie, Australia. Prior to the bit grinding process, each bit had been visually inspected to examine the status of overboard and failures. Table 1 demonstrates the number of grindings and frequency of each failure mode of the collected drill bits. Number of grindings (NG), Button chipped (BC), Sheared-off with body level (SOW), Sheared-off below body level (SOB), Cracked carbide (CC), Lost buttons (LB), Failure at skirt (FS)196 failures cases and 169 overboard bits were investigated among 341 drill bit samples from MINE-A. 54 cases of BC type of bit failure was observed which is the most frequent failure among six other failure. Successively, SOB, SOW and CC type of bit failure were recorded as 50, 45 and 44, respectively. Due to the limited data sample, LB type of bit failure was observed only 3 times while FS did not occur.

Table 1: Number of Bit Grindings and Frequency of each Failure Mode.

\begin{tabular}{|c|c|c|c|c|c|c|c|}
\hline NG & Total Samples & $\mathrm{BC}$ & sow & SOB & $\mathrm{CC}$ & LB & FS \\
\hline 1 & 39 & 1 & 0 & 0 & 2 & 1 & 0 \\
\hline 2 & 70 & 11 & 5 & 7 & 8 & 0 & 0 \\
\hline 3 & 108 & 15 & 16 & 17 & 19 & 2 & 0 \\
\hline 4 & 70 & 12 & 12 & 6 & 11 & 0 & 0 \\
\hline 5 & 23 & 4 & 6 & 6 & 2 & 0 & 0 \\
\hline 6 & 21 & 8 & 7 & 8 & 1 & 0 & 0 \\
\hline 7 & 8 & 3 & 4 & 1 & 1 & 0 & 0 \\
\hline Sum & 341 & 54 & 50 & 45 & 44 & 3 & 0 \\
\hline
\end{tabular}

Number of grindings (NG), Button chipped (BC), Sheared-off with body level (SOW), Sheared-off below body level (SOB), Cracked carbide (CC), Lost buttons (LB), Failure at skirt (FS) 


\section{Effects of bit grindings to failure modes}

It is an apparent theory to propose that the more often a bit is ground, the more likely the bit will fail. This can be proved via calculating the percentage of failure modes in each round of grindings (NG) which is demonstrated in Figure 3 including the number of samples in each grinding round. As can be seen from Figure 3, the number of samples is steadily increased to the $3^{\text {rd }}$ grinding round and rapidly drops after 70 in the $4^{\text {th }}$ grinding. Given that the bits had been consistently collated from one mine, one can expect that the number of recyclable bits was gradually reduced after $3^{\text {rd }}$ grinding round. In other words, bits were gradually discarded due to the accumulated damages through three rounds of grinding and reuse. Except for the LB failure mode (less than 2 or no occurrence), the percentage of bit failure modes is gradually increased up to $3 \mathrm{rd}$ grinding round. The percentage of BC and
SOW type failure modes is steadily increased up to $7^{\text {th }}$ grinding round while the percentage of $\mathrm{CC}$ and SOB type failure modes is fluctuated between 5 th and $7^{\text {th }}$ grinding round due to the lack of samples. The BC, SOW, SOB, and CC can be recognized as the major bit failure modes as they have frequently appeared through the data collection. The relation between the number of bit grinding round and the percentage of bit failure can be analyzed via the linear regression analysis as demonstrated in Figure 4. The analysis was conducted excluding the $7^{\text {th }}$ grinding data of SOB and the $5^{\text {th }}$ to $7^{\text {th }}$ grinding data of $\mathrm{CC}$ as they show abnormal trends due to small number of data sets. As a result, the grinding round and the percentage of bit failure shows a very high correlation with the correlation determination (R2) of 0.86 . This result proves the higher number of bit grindings will cause a higher frequency of bit failures.

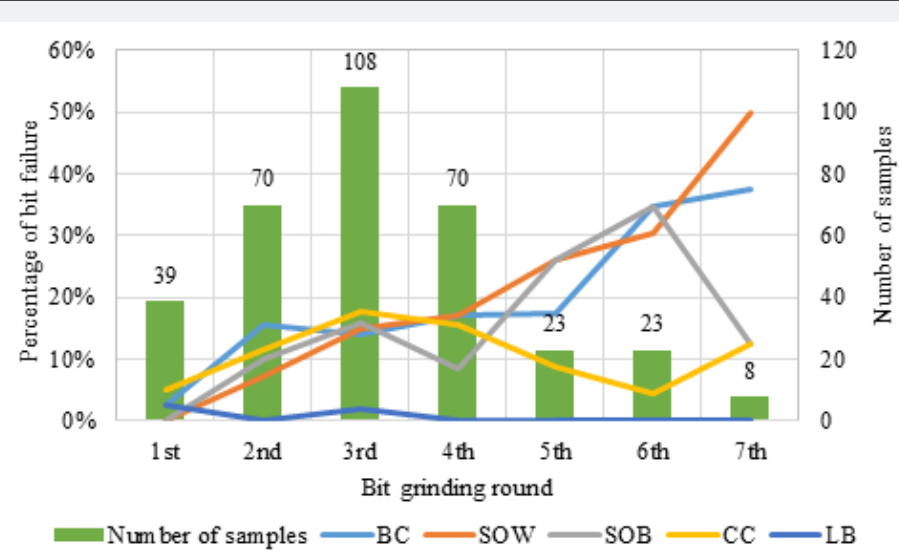

Figure 3: Relationship between the numbers of bit grindings and percentage of failure occurrence with all failure modes: Button chipped (BC), Sheared-off with body level (SOW), Sheared-off below body level (SOB), Cracked carbide (CC), Lost buttons (LB), Failure at skirt (FS).

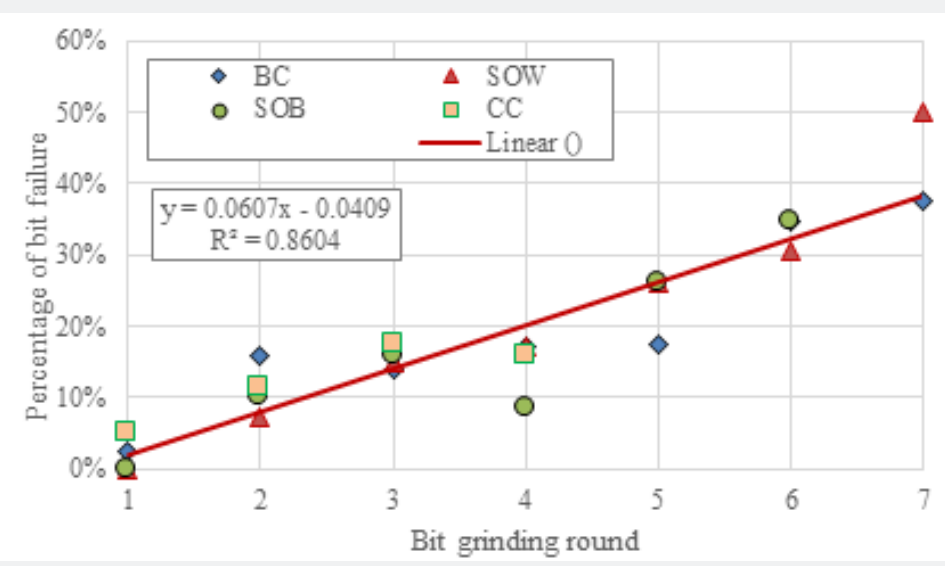

Figure 4: Linear Regression of the Bit Grinding Rounds and the Percentage of Bit Failures.

\section{Comparison between normal bits and overboard bits}

As shown in section 4.1, the overusing bit significantly increases the bit failure frequencies. This section attempts to compare the failure frequencies between the normal bits (NB) and the overboard drill bits (OB). The number of the overboard bits were 169 while 172 samples were classified as the normal bit as the wear flat of buttons was less than $30 \%$ of the button diameter. The comparison has been conducted using the average percentage of bit failure of $1^{\text {st }}$ to $7^{\text {th }}$ grinding rounds in each failure mode. As a result, the average percentage of failures for normal and overboard bits were compared in Figure 5. The overboard bits significantly increase the chance of bit failures. As shown in Figure 5, the av- 
erage percentage of bit failure of the overboard bit in BC, CC and SOW types of failures increases to $23.53 \%, 23.53 \%$, and $16.91 \%$ respectively. The results are $1.68,1.52$, and 2.56 times higher than the average percentage of normal bit failures. Furthermore, the overboard bits significantly increase the average percentage of SOB type bit failure to $26.47 \%$ which is 4.5 times greater than the average percentage of the normal bit failure (5.88\%).

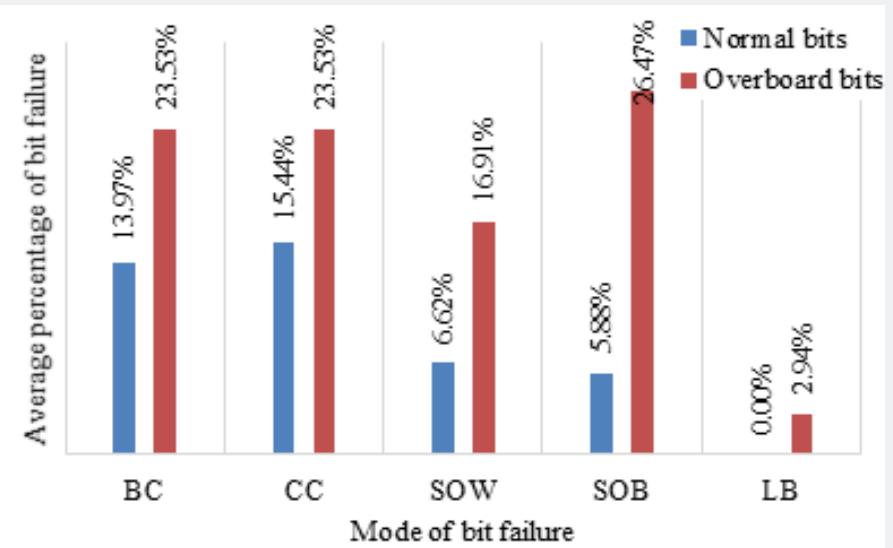

Figure 5: The Average Percentage of Bit Failure of Normal and Overboard Bits in five Typical Bit Failure Modes.

\section{Cost Analysis on the Drill Bits}

In this section, a cost analysis has been conducted to identify how much the operating cost for drill bits might be saved annually. The comparison is conducted between the normal bits with $30 \%$ size of the flat wear and the overboard bits with $50 \%$ and $75 \%$ size of the flat wear. According to the company factsheet, MINE-A has an annual production of 1.8 million tonnes per year from its underground operation. The other necessary parameters are assumed for further calculation as below. The drilling distance of a new drill bit is assumed as $40 \mathrm{~m}$ per bit and $30 \mathrm{~m}$ for the overboard drill bit regardless of the number of grinding round (NG). For instance, drill bits with $1 \mathrm{NG}$ and $7 \mathrm{NG}$ have the same $30 \mathrm{~m}$ travel distance. From this assumption, the drilling distance of one normal drill bit (less than $30 \%$ of WC/Co wear) can be calculated to $250 \mathrm{~m}$ as $40 \mathrm{~m}+(30 \mathrm{~m} \times 7$ times of grinding $)$. In the same way, the drilling distance of $50 \%$ and $75 \%$ overboard bits can be calculated as $190 \mathrm{~m}$ and $130 \mathrm{~m}$ respectively. A specific drill bit, ST68-102mm by MMTC, has a diameter of $102 \mathrm{~mm}$ steel body matrix. The range of the drill bit price is generally from $\$ 400$ to $\$ 500$ Australian Dollar (AUD). In this analysis, the drill bit cost has been assumed as \$400 AUD. Top-hammer drilling bits are used in underground production with hard rock geological conditions. This analysis as- sumed the overall density of $2.7 \mathrm{t} / \mathrm{m}^{3}$ in the MINE-A. In order to calculate the annual operating cost of the drill bit, Cost per metre (CPM) is required which are listed in Table 2 with respect to the size of WC/Co wear flat. The CPM rate is $\$ 1.6$ per metre for the normal bit and $\$ 2.1$ and $\$ 3.1$ per metre for $50 \%$ and $75 \%$ overboard bit respectively. The drilling length per tonne is assumed as $5.48 \mathrm{t} / \mathrm{m} 11$. Since the MINE-A has an annual production of 1.8 million tonnes, the annual operating cost on the drill bit can be calculated as $\$ 525,547$ AUD per year when the rate of bit wear is managed within the range of normal bit $(1,800,000$ (tonne/ year $) \times 1.6(\$ / \mathrm{m}) \times(1 / 5.48)(\mathrm{m} /$ tonne $))$. In order to compare the cost increments with different production rate, 1 and 2.5 million tonnes per year have been analysed as demonstrated in Figure 6. With a production rate of 1 million tonnes per year, the operational cost loss of employing $75 \%$ overboard bits is $\$ 0.28$ million AUD/year comparing with using the normal bits with less than $30 \%$ WC/Co button wear. Furthermore, the operational costs increase as the production rate increases. The cost increments of $75 \%$ overboard bits in comparison of the normal bits of $1.8 \mathrm{Mt}$ and 2.5Mt are \$0.49 million AUD and \$0.68 million AUD respectively. Given that the overboard drill bits cause higher frequencies of drill bit failures, the operating cost will be further increased.

Table 2: Parameters for Cost per Metre (CPM) Rate Calculations.

\begin{tabular}{|c|c|c|c|}
\hline Item & Normal Bit & \multicolumn{2}{|c|}{ Overused Bit } \\
\hline Percentage of WC/Co Button Wear & $30 \%$ & $50 \%$ & $75 \%$ \\
\hline WC/Co Button Worn Down (mm) & 0.5 & 5 & 3 \\
\hline Maximum Bit Grinding Round & 7 & 30 & 30 \\
\hline Drilling Distance per Bit (m) & 40 & 190 & 130 \\
\hline Total Drilling Distance / bit (m) & 250 & 400 & 400 \\
\hline $\begin{array}{c}\text { Drill Bit Cost (example only) } \\
\text { (AUD) }\end{array}$ & 400 & $\$ 2.10$ & $\$ 3.10$ \\
\hline Cost per Metre (CPM) & $\$ 1.60$ & & 3 \\
\hline
\end{tabular}




\section{Insights in Mining Science \& Technology}

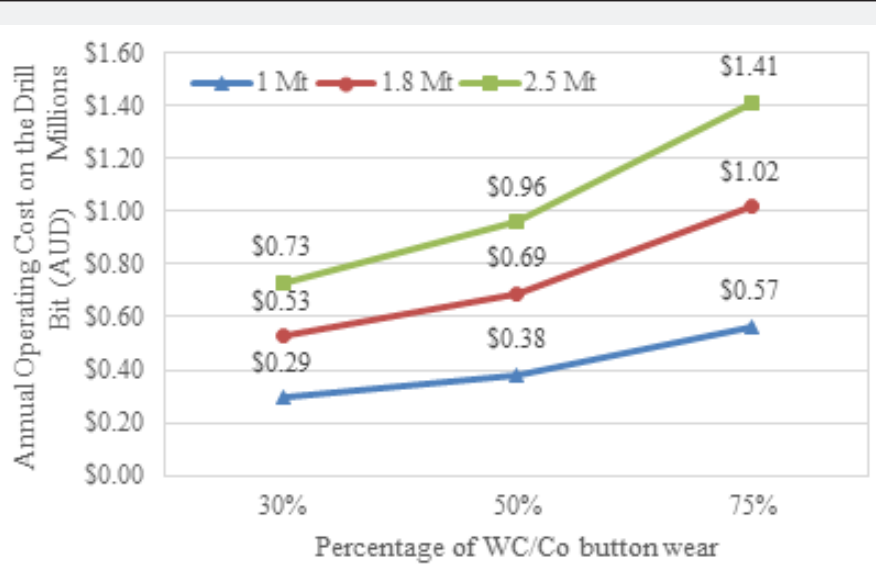

Figure 6: Annual Operating Cost Comparison in Different Production Rate and Percentage of WC/Co Button Wear of Rock Bit (ST68-102mm by MMTC).

\section{Conclusion}

The drill bits are one of the most common consumables but an essential part of the rock excavation process. The maintenance of the drill bit has a direct influence on not only the quality of the drilling but also the efficiency of the operation. The drilling operation in the mining industry often left to contractors and the maintenance of the drill bits is often overlooked. The study aims to analyze the effects of overboard (overused) bits to various failure modes in top-hammer drill bits. $102 \mathrm{~mm}$ drill bit (ST68-102mm by MMTC) was used in underground production at 'MINE-A' and 341 drill bits failure data were collated over the four months at a bit grinding centre at Kalgoorlie, WA, Australia. The collected bits were visually inspected and Button chipped (BC) type failure was revealed as the most frequent failure mode among six other failure modes, i.e., Sheared-off with body level (SOW), Shearedoff below body level (SOB), Cracked carbide (CC), Lost buttons (LB), and Failure at skirt (FS). The relation between the numbers of bit grinding round and the percentage of bit failure had been analyzed using linear regression analysis applying data samples of four major bit failure modes (BC, SOW, SOB, and CC). The result shows a very strong correlation between the grinding round and the percentage of bit failure with the correlation determination (R2) of 0.86. Subsequently, the average percentage of bit failure of the normal bits and the overboard drill bit is compared. The comparison demonstrates that the overboard bits significantly increase the possibility of BC and CC type bit failures approximately 2.5 times greater than the normal bits. Furthermore, the overboard bits significantly affect the SOB type bit failure with 4.5 times higher chance of bit failure than the normal bits. Lastly, a cost analysis of utilizing a different percentage of WC/Co button wear is conducted employing the cost per metre (CPM) rates and annual operating costs. CPM of the normal bits (the bit button wear flat is less than $30 \%$ of the original button diameter) is calculated as $\$ 1.6$ per metre while CPM of $75 \%$ overboard bits is calculated as $\$ 3.1$ per metre. The annual operating cost increases as the production increases. The cost increments of $30 \%$ and $75 \%$ $\mathrm{WC} /$ Co button wear in the annual production of $1.0 \mathrm{Mt}, 1.8 \mathrm{Mt}$ and $2.5 \mathrm{Mt}$ are calculated as $\$ 0.28 \mathrm{M}, \$ 0.49 \mathrm{M}$, and $\$ 0.68 \mathrm{M}$ respectively. The results explicitly show the cost loss of using overboard bits. Given that the increasing bit failure percentage of overboard bits compared with normal bits, the cost loss would be significantly increased when bit wear is improperly managed.

\section{Acknowledgment}

The author would like to acknowledge the support from Mitsubishi Material Trading Corporation and Norton Gold Fields Limited for the study conducted at Curtin University.

\section{References}

1. Zimroz R, Krol R (2009) Failure analysis of belt conveyor systems for condition monitoring purposes. Studia I Materiały 36: 255-270.

2. Mobley RK (1990) An introduction to predictive maintenance (United Sta). Butterworth-Heinemann is an imprint of Elsevier Science.

3. Dhillon BS, Liu Y (2006) Human error in maintenance: a review. Journal of Quality in Maintenance Engineering 12(1): 21-36.

4. Taleb M, Chaib R (2016) Vibration analysis of rotating machines. Mining Science 23: 191-202.

5. Pareto V (1935) The Mind and Society, Dover.

6. Knapp W, Dupuis K, Wilkerson M, Baker C, Tarver C (2012) Agenda of the cema engineering conference bucket elevator committee meeting. Conveyor Equipment Manufacturers Association p. 12.

7. Skotnicka ZB, Bialy W (2011) An analysis of possibilities to use a Pareto chart for evaluating mining machines' failure frequency. Maintenace and Reliability 3: 51-55.

8. Abhishek J, Xiang L, Anand Z, Helen HL, Yinlun H (2011) A sustainability root cause analysis methodology and its application. Computers and Chemical Engineering 35(12): 2786-2798. 
Your next submission with Juniper Publishers will reach you the below assets

- Quality Editorial service

- Swift Peer Review

- Reprints availability

- E-prints Service

- Manuscript Podcast for convenient understanding

- Global attainment for your research

- Manuscript accessibility in different formats ( Pdf, E-pub, Full Text, Audio)

- Unceasing customer service

Track the below URL for one-step submission https://juniperpublishers.com/online-submission.php 